\title{
Time scales for conservative and non-conservative radionuclide transport in the English Channel
}

\author{
R. Periáñez ${ }^{1}$ and C. Miró ${ }^{2}$ \\ ${ }^{1}$ Department of Applied Physics 1, EUITA, Universidad de Sevilla, Ctra Utrera km 1, \\ 41013-Sevilla, Spain \\ ${ }^{2}$ Department of Applied Physics, Universidad de Extremadura, Avda de la Universidad s/n, \\ 10071-Cáceres, Spain
}

\begin{abstract}
A numerical model that simulates the dispersion of radionuclides in the English Channel has been applied to study the dispersion of conservative and non-conservative radionuclides released from La Hague nuclear fuel reprocessing plant. The model is based upon previous work and now is able to simulate dispersion over long time scales (decades), explicitly including transport by instantaneous tidal currents and variable wind conditions. Wind conditions are obtained from meteorological statistics using a stochastic method. Outputs from the model are treated using time-series analysis techniques. These techniques allow the determination of characteristic times of the system, transport velocities and dispersion factors. This information may be very useful to support the decision-making process after an emergency situation. Thus, we are proposing that time-series analysis can be integrated with numerical modelling for helping decision-making in response to an accident. The model is first validated through its application to actual releases of 99-Tc and 125-Sb, and characteristic times for several radionuclides (a conservative one, 137-Cs and 239,240-Pu) are given next. Characteristic transport velocities and dispersion factors have been calculated as well.
\end{abstract}

\section{INTRODUCTION}

A numerical model that simulates the dispersion of conservative radionuclides, ${ }^{137} \mathrm{Cs}$ and ${ }^{239,240} \mathrm{Pu}$ in the English Channel has been developed. The model simulates dispersion over long temporal scales (decades) including tidal mixing and variable wind conditions. In particular, these are obtained from meteorological statistics using a stochastic method. Radionuclide interactions with suspended matter and bed sediments are included in the cases of $\mathrm{Cs}$ and $\mathrm{Pu}$. The model has been tested through comparison of results for real releases from La Hague reprocessing plant with measurements in the Channel.

It is useful to determine characteristic time-scales of a given system for contamination assessments. Many published works concern the determination of time-scales for different systems as the atmosphere, ground waters, rivers, estuaries and the sea [1-6]. Outputs from some numerical experiments carried out with the model have been processed using time-series analysis techniques to calculate characteristic times of the system, transport velocities and dispersion factors. Results from the numerical experiments are supported by experimental evidences. For instance, the transit time from La Hague to Dover Strait in the case of a conservative radionuclide is of a few months, while increases to about 65 years in the case of Pu. Thus, the average transport velocity for this radionuclide is two orders of magnitude lower than the water residual velocity. Characteristic times and transport velocities for reactive radionuclides have not been calculated before. It is finally suggested that the determination of characteristic times and velocities for a system may be an efficient tool to support the decision-making process after a radioactive spill in the aquatic environment.

\section{MATERIALS AND METHODS}

Time-series analysis is a very interesting mathematical technique that can be used in the study of the spatial and temporal evolution of a magnitude when environmental data analysis is required [7]. In this 
paper two techniques, numerical modelling and time-series analysis, are combined. Time-series analysis is applied to study the output from a numerical model that simulates the dispersion of radionuclides in the English Channel. Radionuclides are released from Cap de La Hague nuclear fuel reprocessing plant, in France. Using the time-series analysis, some characteristic time-scales of the system and dispersion factors for any point of interest may be calculated. Having an estimation of these magnitudes may be very useful in the assessment of contamination after an accident: even without running a dispersion model, the time required for a contamination patch to travel from the source to a given point (for instance a coastal town), the time during which such point is being affected by contamination or the speed of the contamination patch may be known, as well as the expected dilution of the patch.

The model used to simulate the dispersion of non-conservative radionuclides in the English Channel is based upon some previous work [8-10]. The first two papers describe a model that simulates tideinduced dispersion of conservative and non-conservative, respectively, radionuclides in the Channel. Thus, they could only simulate relatively short time scales (a few months). The last work describes a long-term dispersion model for non-conservative radionuclides that simulates time scales of the order of decades. This model uses a residual (mean) circulation in the Channel, as well as the annual mean wind speed and direction. These models have now been modified to be able to simulate long-term dispersion (years to decades) of non-conservative radionuclides explicitly including transport by instantaneous tidal currents and variable wind conditions. Tidal currents are stored as tidal constants (amplitudes and phases) obtained after a tidal analysis process [11] carried out over the results of the hydrodynamic model in [8]. A residual wind-induced current database has now been created which includes mean currents produced by winds blowing from the different sectors at their corresponding mean speeds. Wind conditions for a specific day are obtained from the wind rose in the Channel and mean wind velocities using a stochastic method, and the corresponding currents are then obtained from the stored database.

Water-sediment interactions are described using kinetic transfer coefficients $[9,10]$. As an example we can see some results of the new model, applied to simulate actual releases of ${ }^{99} \mathrm{Tc}$ and ${ }^{125} \mathrm{Sb}$ from La Hague, in Fig. 1. A comparison of calculated and measured ${ }^{99}$ Tc concentrations over 1991-92 at a point some $10 \mathrm{~km}$ northeast from La Hague is shown in the top. Below there is a map of the calculated ${ }^{125} \mathrm{Sb}$ distribution in December 1992, which presents the classical banded structure with decreasing concentrations away from the French shore. Also, the transport is directed to the east because the residual circulation in the Channel is directed to Dover.

Several characteristic times have been defined: the time interval during which a given point is affected by contamination, the time required for the arrival of the leading edge of the contamination patch to the point and the time required by the patch to pass the point. The transit time of the radionuclide patch from the source to a given point is defined as well. It is determined from the cross-correlation function of the time-series of radionuclide concentrations at the source and the point of interest [4]. Some characteristic times have also been defined for the bed sediments. The sediment half-life has been defined before [10] as the time in which radionuclide concentration in the sediment decreases in a factor 2. The delay between the maximum concentrations, for a given point, in the dissolved phase and the bed sediment has also been determined. Transport velocities of radionuclides and dispersion factors have finally been obtained.

Numerical experiments have been carried out for a conservative radionuclide, for ${ }^{137} \mathrm{Cs}$ and for ${ }^{239,240} \mathrm{Pu}$. A discharge of an arbitrary magnitude is carried out from La Hague at constant rate during one month. Time series of the resulting radionuclide concentrations at several points of interest are obtained and analyzed to determine the different characteristic times defined above.

\section{RESULTS}

An example of the kind of results which may be obtained from the model is presented in Fig. 2. In the case of a conservative radionuclide, temporal evolutions of dissolved activity concentration at 
a point close to La Hague (point A, $50 \mathrm{~km}$ east from La Hague) and in the centre of Dover Strait ( $246 \mathrm{~km}$ from La Hague) are given. Obviously, there is a delay in the signal as going to the east in the Channel and a decrease in concentrations. The signal is also deformed due to changing winds and turbulent diffusion. The time evolution of concentration in sediments, at the same points, is also presented in Fig. 2 for the case of ${ }^{137} \mathrm{Cs}$. After the initial sediment contamination, there is a slow process of radionuclide redissolution. Thus, bed sediments act as a long-term delayed source of previously released radionuclides. This implies that the contamination also persists in the dissolved phase for a longer time (result not shown).
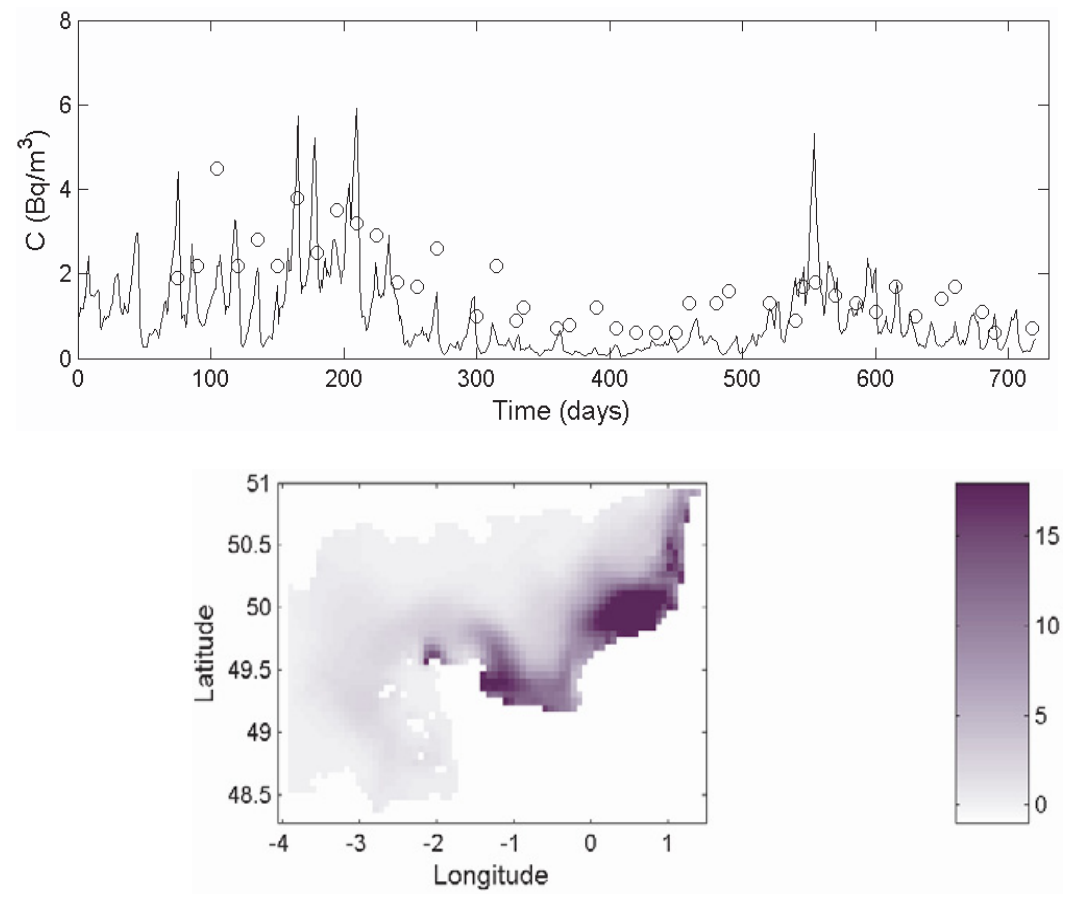

Figure 1. Top; computed (line) and measured (circles) ${ }^{99} \mathrm{Tc}$ concentrations some $10 \mathrm{~km}$ northeast from La Hague. Day 1 corresponds to January 1, 1991. Bottom; computed distribution of dissolved ${ }^{125} \mathrm{Sb}\left(\mathrm{Bq} / \mathrm{m}^{3}\right)$ in December 1992.

A summary of some of the calculated characteristic times from La Hague to Dover Strait is given in Table 1 for the three radionuclides considered. Although they have been evaluated for a number of points along the Channel, only results for the Strait of Dover are presented. The transit time from La Hague to Dover is 75 days for a conservative radionuclide. This value compares with previous calculations of about 3 months [4]. Using the general theory of the age, Delhez and Deleersnijder [2] obtained a value of about 4 months. The transit time of ${ }^{125} \mathrm{Sb}$ from La Hague to Dover has also been estimated from measurements [3], resulting in the range 2-8 months. The transit time of non-conservative radionuclides increases since adsorption to sediments makes these radionuclides less mobile in the aquatic environment. Thus, ${ }^{137} \mathrm{Cs}$ transit time to Dover is $2.7 \pm 0.2$ years and it is $65 \pm$ 4 years in the case of ${ }^{239,240} \mathrm{Pu}$. The mobility of plutonium in the marine environment is much lower than that of conservative radionuclides and caesium. Indeed, it has been estimated from measurements [1] a transit time of plutonium in the eastern Channel ranging from 10 to 50 years. Thus, the significant increase in the plutonium transit time that the model predicts is supported by experimental evidence. 
The sediment half-life increases further from La Hague to the east, although the kinetics of radionuclide redissolution is the same in all the Channel. This is revealing that the sediment acts as a long-term delayed source and that points located to the east are affected by radionuclides released from sediments of the western areas for a longer time. Values of half-lives for Pu are about one order of magnitude larger than for ${ }^{137} \mathrm{Cs}$, which is again indicating that the former is less mobile than the latter.

The delay between maximum concentrations in water and sediment decreases further from the source. As has already been shown [10], when radionuclides are introduced from a continuous source, water and sediment radionuclide partition is not at equilibrium in the source area. However, radionuclide partition between both phases is at equilibrium far from the source location. Consequently, the decrease in the delay with increasing distance from the source is revealing such trend towards equilibrium. Thus, it is confirmed that, from a management perspective, the equilibrium $\mathrm{k}_{\mathrm{d}}$ is an adequate parameter to describe radionuclide speciation only far from the source location in the case of non-instantaneous releases. Nevertheless, if the radionuclide is highly reactive the adsorption kinetics will be faster and equilibrium will be reached sooner, as it is the case with plutonium.
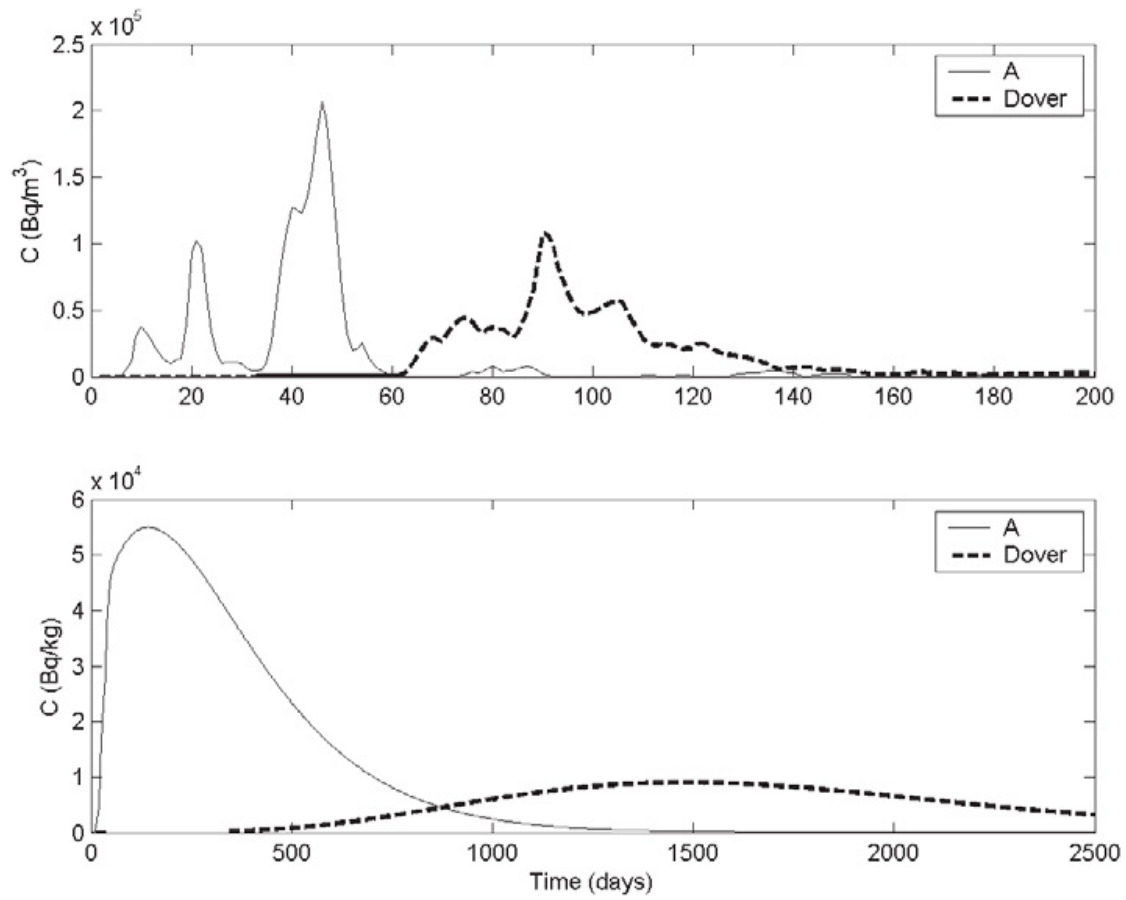

Figure 2. Up: computed time evolution of dissolved concentration of a conservative radionuclide at a point $50 \mathrm{~km}$ east from La Hague (A) and Dover Strait. Down: the same but sediment concentration in the case of 137-Cs.

Table 1. Characteristic times for radionuclide transport evaluated at the Strait of Dover for a release occurring at La Hague plant. $T_{t}$ transit time, $T_{h}$ sediment half-time, $T_{\text {lag }}$ delay between maximum concentrations in the dissolved phase and in the bed sediment, $v$ mean velocity along the Channel and DF dispersion factor (dimensionless). Note the different units for Pu characteristic times.

\begin{tabular}{|l|c|c|c|c|c|}
\hline & $\mathrm{T}_{\mathrm{t}}$ & $\mathrm{T}_{\mathrm{h}}$ & $\mathrm{T}_{\mathrm{lag}}$ & $v(\mathrm{~km} /$ day $)$ & $\mathrm{DF}$ \\
\hline conservative & $75 \pm 7 \mathrm{~d}$ & - & - & $3.4 \pm 0.3$ & 7.08 \\
\hline $137-\mathrm{Cs}$ & $1000 \pm 80 \mathrm{~d}$ & $425 \pm 30 \mathrm{~d}$ & $3 \pm 25 \mathrm{~d}$ & $0.20 \pm 0.04$ & 6.99 \\
\hline $239,240-\mathrm{Pu}$ & $65 \pm 4 \mathrm{y}$ & $>9 \mathrm{y}$ & $0 \pm 4 \mathrm{y}$ & $0.010 \pm 0.003$ & 8.31 \\
\hline
\end{tabular}


For a conservative radionuclide, average transport velocity is about $3.5 \mathrm{~km} /$ day, in agreement with the previous estimation in [9] with a short-term dispersion model: $2.8 \mathrm{~km} /$ day. The velocities are significantly reduced for non-conservative radionuclides since water-sediment interactions make them less mobile. Particularly, plutonium average velocity is two orders of magnitude lower than the residual currents responsible of the transport of conservative elements. This is again in excellent agreement with the results, from measurements, of Boust et al. [1]: these authors found average velocities ranging between some $\mathrm{km}$ per year to some tens of $\mathrm{km}$ per year (i.e., of the order of $10^{-3}$ to $10^{-2} \mathrm{~km} / \mathrm{day}$ ). Dispersion factors at Dover are about 7 for the three considered radionuclides.

Characteristic times, average velocities and dispersion factors for a given environment may be useful to support the decision making process after an emergency situation. For instance, the time of arrival of a contamination patch to a given sensible point, the time during which the point is to be affected by contamination and the maximum expected concentration may be quickly estimated from them. These estimations may be carried out under more or less conservative approaches and for radionuclides with different geochemical behaviours. If more details are required in a practical problem, a full model run may be carried out to complete results. Of course, in the case of highly reactive elements (as $\mathrm{Pu}$ ) the calculation of transit times may not be relevant in this sense because of their extremely low mobility. However, valuable information about their environmental behaviour is obtained.

\section{CONCLUSIONS}

A model to describe the dispersion of non-conservative radionuclides over long time scales (years to decades) in the English Channel has been developed from previous work. The new aspect of this model is that it explicitly includes tidal mixing (by instantaneous tidal currents) and variable wind conditions, which are obtained from meteorological statistics. This new model formulation was tested through its application to simulate the dispersion of actual ${ }^{99} \mathrm{Tc}$ and ${ }^{125} \mathrm{Sb}$ releases from La Hague reprocessing plant. Computed concentrations of these radionuclides were, in general, in agreement with measurements.

Some numerical experiments were carried out once the model was validated. Model output from these experiments were processed using time-series analysis techniques to evaluate characteristic times for water and sediments, average transport velocities and dispersion factors. These magnitudes were calculated for a conservative radionuclide, for ${ }^{137} \mathrm{Cs}$ and for ${ }^{239,240} \mathrm{Pu}$. The computed transit time from La Hague to Dover in the case of a conservative radionuclide was a few months, and increased to about 65 years in the case of plutonium. Similarly, average velocity for this radionuclide was two orders of magnitude lower than the water residual velocity. These results are supported by experimental evidence, and it is worth commenting that characteristic times and velocities have not been calculated using numerical models before in the case of non-conservative radionuclides.

Essentially the same results were obtained if the annual mean wind or stochastic winds were used. This confirms results from previous modelling works. Also, it was confirmed that the equilibrium $\mathrm{k}_{\mathrm{d}}$ should be used with care for contamination assessments: water-sediment radionuclide partition is not at equilibrium close to the source location. The meaning of close depends on the geochemical behaviour (reactivity) of the radionuclide.

Characteristic times, average velocities and dispersion factors for a given environment may be useful to support the decision making process after an emergency situation. For instance, the time of arrival of a contamination patch to a given sensible point, the time during which the point is to be affected by contamination and the maximum expected concentration may be quickly estimated from them. These estimations may be carried out under more or less conservative approaches and for radionuclides with different geochemical behaviour. If more details are required in a practical problem, a full model run may be carried out to complete results.

Although the model and the time-series analysis have been applied to the English Channel, these techniques may of course be applied to any other marine, estuarine or freshwater environment. 


\section{Acknowledgments}

R. Periañez is indebted to the Spanish Ministerio de Educación y Ciencia for a fellowship to stay during three months in the University of Wales, where part of this work was carried out.

\section{References}

[1] Boust, D., Colin, C., Leclerc, G. and Baron, Y. Radioprot Col 32 (1997), 123-128.

[2] Delhez, E.J. and Deleersnijder, E. J Mar Syst 31 (2002), 279-297.

[3] Guegueniat P., Bailly du Bois P., Gandon R., Salomon J.C., Baron Y. and Leon R., Estuar Coastal Shelf Sci 39 (1994), 59-74.

[4] Salomon J.C., Breton M. and Guegueniat P. J Mar Syst 6 (1995), 515-527.

[5] Braunschweig, F., Martins, F., Chambel, P. and Neves, R. Ocean Dynamics 53 (2003), 137-145.

[6] Holzer, M. and Hall, T.M. J Atmos Sci 57 (2000), 3539-3558.

[7] Hewit, C.N. Methods of Environmental Data Analysis. Elsevier, London, 1992,

[8] Periáñez, R. and Reguera, J. J Environ Radioact 43 (1999), 51-64.

[9] Periáñez, R. J Environ Radioact 49 (2000), 259-277.

[10] Periáñez, R. Estuar Coastal Shelf Sci 56 (2003), 5-14.

[11] Periáñez, R. Modelling the Dispersion of Radionuclides in the Marine Environment. SpringerVerlag, Heidelberg, 2005. 